\title{
Choosing Wisely around the world
}

$\mathrm{M}$

ore countries are joining an international campaign to combat overuse in health care. The Choosing Wisely campaign began in 2012 in the United States to change the "more-is-better" culture of medicine by creating checklists of tests and treatments that doctors should question with their patients. For example, the campaign recommends against prescribing antibiotics for viral infections.

The checklists sparked a conversation about appropriate care that has since gone global, including the launch of Choosing Wisely Canada in 2014. The Netherlands, England, Japan, Australia, New Zealand, Germany, Italy, Switzerland, Wales and Denmark have launched similar campaigns.

"It's estimated that a third of all medical care is waste, meaning it doesn't have value and can be harmful," says Dr. Wendy Levinson, chair of the Canadian campaign. "That's highly relevant to doctors; we don't get up in the morning to save money for the health care system, but we do get up to deliver good quality care and prevent harm to our patients."

\section{Early progress}

The US and Canada served as the testing grounds for Choosing Wisely, and have seen the most progress to date.

In America, over 100 national, regional and state medical organizations have released more than 70 lists of tests and procedures they say are overused. Health organizations across the country have used these recommendations.

Notably, Cedars-Sinai Medical Center in Los Angeles slashed unnecessary health care costs by more than $\$ 4$ million in one year by programming over 100 Choosing Wisely recommendations into its electronic medical records (EMR) system. For example, the system reminds physicians not to prescribe benzodiazepines for insomnia in patients over 65 , because these drugs increase the risk of falls. As a result, prescribing of benzodiazepines to older patients dropped $30 \%$.

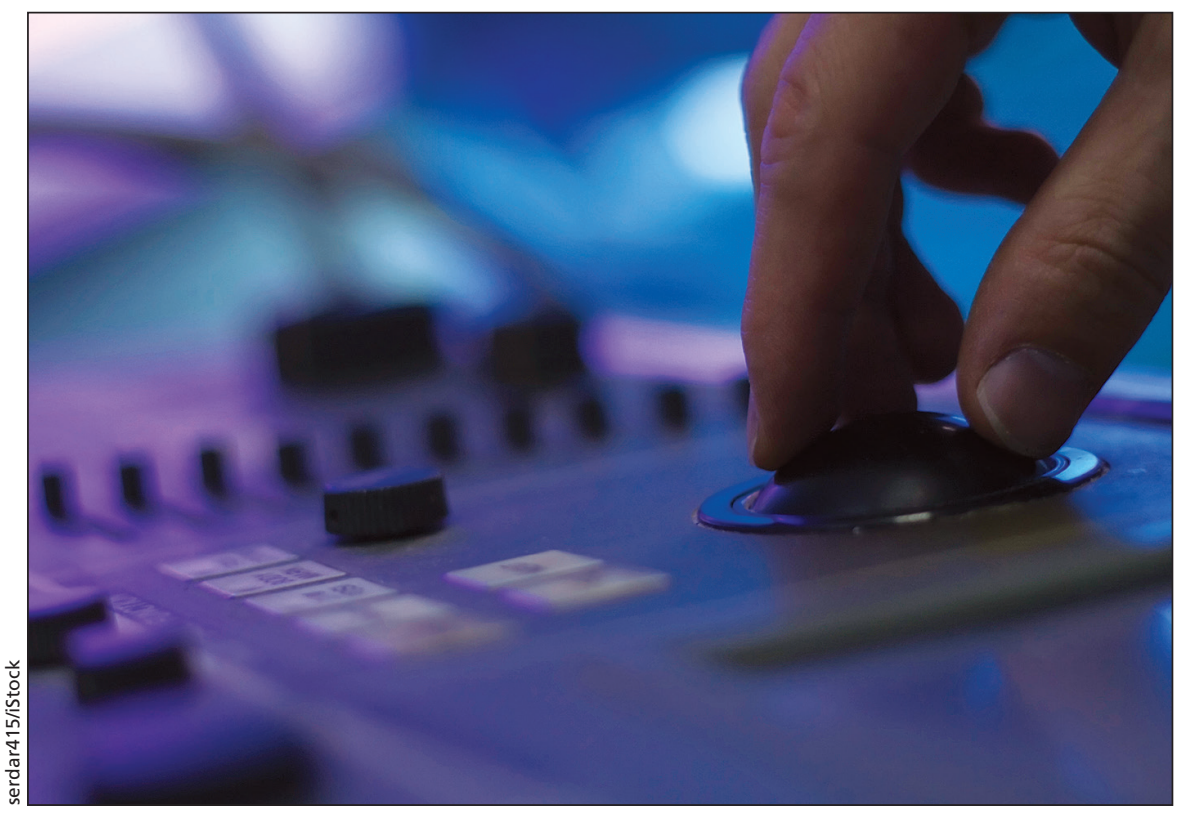

More medical organizations worldwide are encouraging physicians and patients to talk about unnecessary diagnostic tests and care.

Since 2013, the ABIM (American Board of Internal Medicine Foundation) has also awarded \$2.5 million in grants for projects to raise public and physician awareness about Choosing Wisely. This month, the foundation announced a new round of grants for health system initiatives to implement at least three campaign recommendations, including reducing the use of antibiotics for viral infections by at least $20 \%$ over the next three years.

Canada has seen similar success since launching its campaign in April 2014, says Levinson. More than 40 medical societies have joined and 29 have published lists of tests and procedures to question, including 49 new recommendations released June 2.

Some hospitals have developed point-of-care tools specifically to implement Choosing Wisely recommendations. Others have focused on education campaigns. By implementing an EMR intervention like the one at CedarsSinai, North York General Hospital in Toronto has cut emergency department laboratory testing by $40 \%$, without a change in outcomes.
Now, "the gap for us is broader patient education and engagement in the creation of our materials," says Levinson. Consumer Reports, an American nonprofit consumer organization, has shouldered this role south of the border, but no equivalent exists in Canada, she says.

\section{Starting in England}

The North American method - create lists, raise awareness and foster grassroots implementation - has become the model for other countries' campaigns.

The United Kingdom's Academy of Medical Royal Colleges is among the latest Choosing Wisely adopters. Prudent use of health resources isn't a new concept in the UK. Since 1999, the National Institute for Health and Care Excellence has recommended more than 800 clinical interventions for divestment based on variations in clinical practice (an indicator of overuse).

But there are still major challenges to changing practice at the bedside, says Dr. Angelika Zarkali, clinical lead on the campaign for England's National Health Service. "We don't have as 
much an issue of physician commercial interest as the States might, but we do have very easy access to treatment, and sometimes it's easier for physicians to order than to explain." Internal surveys show that $80 \%$ of physicians agree with the campaign, but many are worried how patients will perceive the initiative, says Zarkali.

The UK campaign launched in May and is still assembling specialty-society partners.

\section{Screening in Japan}

Japan is another recent adopter, and a champion for Choosing Wisely in Asia. Dr. Yasuharu Tokuda of the Japan Community Health Care Organization started the campaign in 2014, largely in response to rampant direct-to-consumer preventive screening. The first Choosing Wisely conference in Japan produced five recommendations mostly aimed at curbing unnecessary testing, such as tumour-marker screening for asymptomatic adults.

Now, "we are setting up a working group inside the Japanese Society for Quality and Safety in Health Care," says Tokuda. In addition to publishing patient and physician recommendations, "we would like to organize an Asian collaboration for campaigns between Japan, South Korea and other countries."

\section{The Netherlands}

Most international campaigns have been underway for only a few months, but the Netherlands is one exception. The Dutch Association of Medical Specialists started work in 2013 and began publishing lists of procedures to avoid in 2014.

The campaign has four parallel initiatives for recommending "wise choices," promoting shared decision-making with patients, evaluating quality and efficiency of care and identifying variations in practice.

Dr. Marjon Kallewaard, director of quality for the association, says the research arms of the campaign are particularly important. "About half of health care isn't evidence-based," she estimates. "Now half of the specialty societies have programs in which they study the most important things we don't know, and where in daily practice we don't have an answer for the patient."

In addition to reducing unnecessary care, knowledge-gap studies also stand to save health systems a lot of money, Kallewaard predicts. "In gynecology, for every Euro invested in these studies, the output is three." - Lauren Vogel, CMAJ

CMAJ 2015. DOI:10.1503/cmaj.109-5111 